\title{
3 Research Square

\section{Nitric Oxide Could Allay Arsenic Phytotoxicity in Tomato (Solanum lycopersicum L.) by Modulating Photosynthetic Pigments, Phytochelatin Metabolism, Molecular Redox Status and Arsenic Sequestration}

Abazar Ghorbani ( $\square$ Ghorbani62a@gmail.com )

University of Mohaghegh Ardabili

\section{Leila Pishkar}

Islamshahr Branch, Islamic Azad University, Islamshahr, Iran

Nasim Roudbari

Faculty of Biology, Islamic Azad University, Kahnouj Branch, Kerman, Iran

Necla Pehlivan

Recep Tayyip Erdoğan University

Chu Wu

Yangtze University

\section{Research Article}

Keywords: Solanum lycopersicum L., Arsenic toxicity, Sodium nitroprusside, Phytochelatin, Vacuolar sequestration, Oxidative stress

Posted Date: December 18th, 2020

DOl: https://doi.org/10.21203/rs.3.rs-129421/v1

License: (c) (i) This work is licensed under a Creative Commons Attribution 4.0 International License. Read Full License 


\section{Abstract}

Background: Plants do not always have the genetic capacity to tolerate high quantities of (As) which does not only arrest the plant growth, but commit potential health risks by dietary bioaccumulation. However, the interplay between the tomato plants and As-NO driven molecular cell dynamics are obscure. Hence, seedlings were treated with As $(10 \mathrm{mg} / \mathrm{L})$ alone or in combination with $100 \mu \mathrm{M}$ sodium nitroprusside (SNP, NO donor) and $200 \mu \mathrm{M}$ 2-(4-carboxyphenyl)-4,4,5,5-tetramethylimidazoline-1-oxyl-3oxide (CPTIO, NO scavenger).

Results: SNP immobilized the As in the roots and reduced the shoot translocation by up-regulating the transcriptional expression of the PCS, GSH1, MT2 and $A B C 1$. SNP further restored the growth retardation by modulating the chlorophyll and proline metabolism, increasing $\mathrm{NO}$ accumulation and stomatal conductance along with a clear crosstalk between the activity of antioxidants as well as glyoxalase I and II leading endogenous $\mathrm{H}_{2} \mathrm{O}_{2}$ and $\mathrm{MG}$ decrease.

Conclusion: Higher PCs and glutathione accumulation helped to protect photosynthetic apparatus, however, CPTIO reversed the protective effects of SNP, authenticating the role of NO in the As toxicity alleviation.

\section{Introduction}

Today, anthropogenic activities, including irrigation of crops with contaminated groundwater and uncontrolled use of herbicides and pesticides, have led to increased arsenic (As) pollution in waters, sediments and soils. This has resulted a sharp risk for plants. Owing to its high mobility, As easily enters into the plant cell cytosol which might later on develop human health risk factors due to the low yet chronic exposure by entering the food web [32, 71]. The International Agency for Research on Cancer (IARC) and Environmental Protection Agency (EPA) has already identified As as amongst the most carcinogenic heavy metal(oid)s in Group I as it does disrupt the different physiological processes in various organs [8].

AsIll and AsV are the main inorganic forms of As in the soil, which AsIll is more toxic compared to AsV due to its greater mobility and solubility [36]. As has been shown to have negative effects on the photosynthetic capacity, biomass and reproduction, thereby reduced plant growth and yield [2, 46]. Several works have reported that As disrupts vital metabolic pathways such as respiration, transpiration and photosynthesis [43, 22]. In addition, Yadav [68] indicated that the toxic As levels generates oxidative stress in plants by damaging the photosynthetic apparatus itself, by disrupting the electron transfer chains and the redox balance. Methylglyoxal (MG) on the other hand, is another stress-triggered noxious compound and can show irreversible injurious effects on plants [40]. Reactive oxygen species and MG produced by plants under stressful conditions reacts with biomacromolecules (e.g. DNA, proteins, membrane lipids etc.) in the cell and cause dramatic damages to their structure and functionality [69]. Generated reactive oxygen species (ROS) and MG in various plants under As toxicity has also recently 
been reported $[2,46,48]$. Thus, it is clear today that plants are equipped with enzymatic and nonenzymatic antioxidant defense systems to resist these oxidative bursts and maintain ROS homeostasis. a-tocopherols, glutathione (GSH), ascorbic acid (AsA) and phenolic compounds are among the most important non-enzymatic antioxidants. Contrarily, Catalase (CAT), ascorbate peroxidase (APX), superoxide dismutase (SOD), dehydroascorbate reductase (DHAR) and monodehydroascorbate reductase (MDHAR) are the enzymatic antioxidants of the plants [5]. The glyoxalase system is another defense mechanism in plants regulated by the two enzymes: glyoxalase (Gly) I and Gly II, that increases plant tolerance to stress by detoxifying the MG [30]. Therefore, a strong defense system consisting glyoxalase system and the antioxidant systems can effectively increase plant tolerance to external abiotic stresses such as arsenic toxicity.

NO, an ubiquitous small signaling molecule, is well-known to be involved in the plant response to several abiotic stress by activating various signaling pathways in cells. In addition, NO involved in vital physiological processes, including energy transform, stomatal closure, secondary root initiation, seed germination and floral regulation $[6,16,57]$. Hermes et al. [33] reported that the external NO application alleviates oxidative stress by mediating target gene expression. NO has also been reported to be involved in the regulation of the AsA-GSH cycle enzymes and ROS scavenge $[26,70]$. Singh et al. [58] further reported that NO supplementation restored the halted growth of the As-stressed rice plants by upregulating the expression of the $\gamma$-glutamylcysteine synthetase gene and improving the AsA-GSH ratio as well as reducing the As up-take. However, more detailed data linking plant defense in the metabolic pathways is needed to understand the substantial role of NO in improved As tolerance.

To deepen our understanding of external NO application in the improvement of plant As stress adaptation, we used sodium nitroprusside (SNP) as a NO donor and 2-(4-carboxyphenyl)-4,4,5,5tetramethylimidazoline-1-oxyl-3-oxide (CPTIO) as a NO scavenger for toxic As levels in tomato (Solanum lycopersicum L.). Apart from the well-known antioxidant properties of NO, the role of $\mathrm{NO}$ in the expression of genes involved in the phytochelatins (PCs) biosynthesis has been evaluated as a novel target for NOinduced plant As toxicity responses. Resulted data coupled with the examined antioxidant defense system, glyoxalase pathway and AsA-GSH cycle data that could have potential implications for marginal agricultural practices in the As-polluted soil in order to monitor and ensure food security and safety in the long-run.

\section{Material And Methods}

\section{Plant material and experimental design}

After sterilized by $0.5 \%$ sodium hypochlorite with subsequent washes $\left(\mathrm{dH}_{2} \mathrm{O}\right)$, tomato seeds $(S$. lycopersicum var. 2270) were germinated in a container filled with the pre-autoclaved peat moss. Seedlings (10-day-old) then were transferred to $1 / 2$-strength Hoagland pots and kept at $25 / 18{ }^{\circ} \mathrm{C}, 65-70 \%$ humidity and $16 \mathrm{~h}$ day $/ 8 \mathrm{~h}$ night photoperiod with $400-450 \mu \mathrm{mol} \mathrm{m} \mathrm{m}^{-2} \mathrm{~s}^{-1}$ luminous intensity. Hoagland solution was replaced every 4 days and oxygenated by an air pump. After 15 days of an acclimation 
period, 30 days old tomato seedlings were exposed to $10 \mathrm{mg} / \mathrm{L}$ arsenic $\left(\mathrm{NaAsO}_{2}\right), 100 \mu \mathrm{M}$ sodium nitroprusside (SNP, NO donor) and $200 \mu \mathrm{M}$ 2-(4-carboxyphenyl)-4,4,5,5-tetramethylimidazoline-1-oxyl-3oxide (CPTIO, a NO scavenger) in a $1 / 2$-strength Hoogland nutrient solution. As and SNP concentrations were selected based on the plots of our own pre-liminary data. The treatment concentrations were as follows: (a) $1 / 2$ strength Hoagland (control), (b) $10 \mathrm{mg} / \mathrm{L} \mathrm{As}$, (c) $10 \mathrm{mg} / \mathrm{L} \mathrm{As}+100 \mu \mathrm{M} \mathrm{SNP,} \mathrm{(d)} 10 \mathrm{mg} / \mathrm{L} \mathrm{As}$ + $200 \mu \mathrm{M}$ cPTIO, (e) 10 mg/L As + $100 \mu \mathrm{M} \mathrm{SNP}+200 \mu \mathrm{M}$ cPTIO. 45-day-old seedlings were harvested after 15 days of related exposures. Right after measuring the plant height, samples were stored at $-80^{\circ} \mathrm{C}$ for further biochemical and molecular analyses. To determine total dry weight and the As concentration, seedlings were oven-dried at $72{ }^{\circ} \mathrm{C}$ for $24 \mathrm{~h}$.

\section{Photosynthetic pigments, chlorophyll fluorescence and gas exchange parameters}

The contents of chlorophyll $\mathrm{a}, \mathrm{b}$ and carotenoids were determined according to the Lichtenthaler [41] Analysis was performed using the acetone (80\%) as the extraction solvent. Chlorophyll fluorescence and leaf gas exchange parameters of tomato seedlings were measured by a PAM fluorometer (Walz; PAM 2500) and portable gas exchange system (GFS-3000; Walz) from 8 to 9 a.m.

\section{As and NO determinations}

The concentration of As were determined using an ICP-MS (Agilent $7500 \mathrm{cx}$ ) after washing both leaf and root tissues with $\mathrm{dH}_{2} \mathrm{O}(4 \mathrm{X})$ and digesting the samples in the $\mathrm{HNO}_{3}: \mathrm{H}_{2} \mathrm{O}_{2}(1: 4$ ratio). Thereafter homogenizing the fresh root and leaf tissues with $4 \%$ zinc diacetate and cold acetic acid buffer $(50 \mathrm{mM}$, $\mathrm{pH}$ 3.6), the homogenate was centrifuged at $12.000 \times \mathrm{g}$ for $20 \mathrm{~min}$. Then, Caracol was added to the supernatants and samples were vortexed. After filtration, Greiss reagent was mixed and samples incubated at RT for $30 \mathrm{~min}$. The NO content was determined spectrophotometrically at $540 \mathrm{~nm}$ based on the prepared standard curve of $\mathrm{NaNO}_{2}$ using the method previously described by $\mathrm{Hu}$ [34].

\section{Proline and soluble sugar contents}

To measure proline based on the Bates method [9] fresh leaves were homogenized in sulfosalicylic acid, then centrifuged at $12.000 \times \mathrm{g}$ for $20 \mathrm{~min}$. After adding both glacial acetic acid and acid ninhydrin to the supernatant, the obtained solution was incubated at $100^{\circ} \mathrm{C}$ for $1 \mathrm{~h}$. After cooling the samples on the ice bath and adding toluene to each, the spectrophotometric measurements were recorded at $520 \mathrm{~nm}$ absorbance.

The soluble sugar content was analyzed using the protocol released by Shi et al. [55] and the basic anthrone method. After the leaves submerged into the ethanol (80\%) for $30 \mathrm{~min}$ at $80^{\circ} \mathrm{C}$, the anthrone 


\section{Lipid peroxidation and hydrogen peroxide $\left(\mathrm{H}_{2} \mathrm{O}_{2}\right)$ contents}

Heath and Packer [31] method was used in order to estimate the oxidized lipids by malondialdehyde (MDA) contents. After extracting the fresh leaves using 2-thiobarbituric acid $(0.65 \%)$ and trichloroacetic acid $(10 \%)$, samples were centrifuged at $12.000 \times \mathrm{g}$ for $15 \mathrm{~min}$, then the optical density of the supernatants was recorded at 532 and $600 \mathrm{~nm}$.

For $\mathrm{H}_{2} \mathrm{O}_{2}$, after extracting the fresh tomato leaves in thiobarbituric acid $(0.1 \%)$ and centrifuging the mixtures at $12.000 \times \mathrm{g}$ for $15 \mathrm{~min}$, phosphate buffer $(10 \mathrm{mM}, \mathrm{pH} 7.0)$ and $1 \mathrm{M}$ potassium iodide were added to the supernatants, then the absorbances were read at $390 \mathrm{~nm}$. The $\mathrm{H}_{2} \mathrm{O}_{2}$ contents were calculated by a previously described method of Velikova et al. [64].

\section{Enzyme extraction assays}

Fresh tomato leaves were extracted using the buffer including polyvinylpyrrolidone (1\%), Triton X-100 $(0.5 \%)$ and potassium phosphate $(100 \mathrm{mM}, \mathrm{pH} 7.0)$. Ascorbate $(2 \mathrm{mM})$ was then added to the extraction mixture to assay ascorbate peroxidase activity. After centrifugation at $15.000 \times \mathrm{g}$ at $4{ }^{\circ} \mathrm{C}$ for $20 \mathrm{~min}$. Resulted supernatants were used to measure the protein and enzyme activities.

Superoxide dismutase activity was calculated by measuring the photochemical reduction of nitroblue tetrazolium as previously described by Dhindsa and Matowe [15]. Catalase was measured by monitoring the decrease in the $\mathrm{H}_{2} \mathrm{O}_{2}$ concentration at $240 \mathrm{~nm}$ for $2 \mathrm{~min}$. as per Aebi [1]. The ascorbate peroxidase activity was determined according to Nakano and Asada [47] by recording the oxidation of the ascorbate induced by $\mathrm{H}_{2} \mathrm{O}_{2}$ for 2 min at $290 \mathrm{~nm}$. The activity of glutathione reductase was further measured by Foyer and Halliwell [21] via recording the oxidation of NADPH by oxidized glutathione at $340 \mathrm{~nm}$.

Glyoxalase (Gly) I activity was analyzed with the method of Hasanuzzaman et al. [30] by recording the 1 min increase in the absorbance (at $240 \mathrm{~nm}$ ) of the reaction containing $100 \mathrm{mM}$ potassium-phosphate buffer (pH 7.0), MG (3.5 mM), $1.7 \mathrm{mM} \mathrm{GSH}$, magnesium sulfate $(15 \mathrm{mM})$ and enzyme extracts. The activity of Gly II was determined with Principato et al. (1987) by monitoring the increase in the absorbance of the mixture (protein extract, $100 \mathrm{mM}$ Tris-HCl buffer (pH 7.2), S-D-lactoylglutathione (1 $\mathrm{mM}$ ) and 5,5'-dithiobis (2-nitrobenzoic acid) (DTNB, $0.2 \mathrm{mM}$ )) at $412 \mathrm{~nm}$ for $1 \mathrm{~min}$.

By monitoring the difference in the porphobilinogen concentration for $15 \mathrm{~min}$ at $553 \mathrm{~nm}$, the $\delta$ aminolevulinic acid dehydratase was measured according to Jain and Gadre [35]. Proline dehydrogenase and $\Delta^{7}$-pyrroline-5-carboxylate synthetase activities were also measured according to the methods 
previously introduced by Charest and Phan [12] and Sumithra et al. [63], respectively. Chlorophyllase activity was determined based on the protocol of Costa et al. [13].

The protein contents were basically calculated as described by Bradford [10] using the serial aliquots of bovine serum albumin standard.

\section{Ascorbic acid, glutathione and phytochelatin contents}

After homogenizing the fresh root tissues with metaphosphoric acid (5\%) containing EDTA (1 mM) and centrifuging the homogenate at $12.000 \times g$ for 10 min, the supernatants were used to measure the following AsA and GSH contents. To determine AsA, target supernatants were neutralized by the K-P buffer $(0.5 \mathrm{M}, \mathrm{pH} 7.0)$ and the oxidized AsA in the extract was reduced using $0.1 \mathrm{M}$ dithiothreitol. After adding 1 unit of ascorbate oxidase and K-P buffer $(100 \mathrm{mM}, \mathrm{pH} 7.0)$ into the samples, both the total and the reduced AsA were determined by spectrophotometric reads at $265 \mathrm{~nm}$. The reduced AsA contents were calculated by the standard curve of AsA [12] while oxidized AsA (DHA) was determined using the following formula: Oxidized AsA = total AsA - reduced AsA.

A reaction mixture including the supernatant, NADPH $(0.3 \mathrm{mM})$, DTNB $(6 \mathrm{mM})$ and $10 \mathrm{U} \mathrm{mL}^{-1}$ glutathione reductase was applied to measure the total glutathione (GSSG $+\mathrm{GSH}$ ) amount in the samples. After incubation of the reaction mixture (supernatant, triethanolamine $(50 \%, \mathrm{v} / \mathrm{v})$ and 2-vinylpyridine) at $25^{\circ} \mathrm{C}$ for 20 min, the GSSG contents were calculated by the reads at $412 \mathrm{~nm}$. Subtracted GSSG contents from the total glutathione were analyzed according to a previously described GSH analysis method of Gill et al. [24].

Phytochelatin concentration was measured by the extraction of the non-protein thiols, described by De Vos et al. [14]. After homogenizing the fresh tomato leaf and root tissues in the sulfosalicylic acid (3\%) and centrifuging the mixtures at $12.000 \times g$ at $4^{\circ} \mathrm{C}$ for $15 \mathrm{~min}$, the supernatants were mixed with the reaction mixture including phosphate buffer $(120 \mathrm{mM}, \mathrm{pH} 7.5), 5,5^{\prime}$-dithiobis (2-nitrobenzoic acid) (0.6 $\mathrm{mM}$ ) and EDTA ( $5 \mathrm{mM})$. The phytochelatin content was estimated after subtracting the GSH content from non-protein thiols recorded at $412 \mathrm{~nm}$.

\section{Gene expression pattern}

Total RNA extraction from leaves and roots of tomato seedlings separately was performed manually by TRIzol reagent (Invitrogen, USA) based on the manufacturer's protocol. After DNasel treatment, RNA was reverse-transcribed into the first-strand cDNA by reverse transcriptase, oligo (dT) primers and dNTPs (10 $\mathrm{mM}$ ) (Thermo Scientific, Germany). Quantitative PCR analysis of the target genes was performed by Maxima SYBR Green/ROX qPCR Master Mix (Thermo scientific) using a C1000TM Thermal Cycler instrument (BioRad). The PCR reaction set up was as follows: 2 min at $94^{\circ} \mathrm{C}$ initial, followed by 40 cycles of $15 \mathrm{~s}$ at $95^{\circ} \mathrm{C}$ (denaturation), $45 \mathrm{~s}$ at $60^{\circ} \mathrm{C}$ (annealing) and $25 \mathrm{~s}$ at $72^{\circ} \mathrm{C}$ (extension). The tomato Actin 
gene and the $2^{-\Delta \Delta C t}$ method of Livak and Schmittgen [42] were used for the normalization and the data analysis, respectively. The primers used in the study were designed by an online software (Primer3) and tested using OLIGO5 analyzer software (Table 1).

Table 1

Primers used for real time qPCR reactions

\begin{tabular}{|lll|}
\hline Gene name & 5'-primer-3' & Accession No. \\
\hline Phytochelatin synthase (PCS) & F: & Solyc09g072620.2.1 \\
& GAAGGTCTGGTTTGTCGGAT & \\
& R: CCATTCCCATTCCCATTTAC & \\
$\begin{array}{l}\text { Gamma-Glutamylcysteine synthetase } 1 \\
\text { (GSH1) }\end{array}$ & F: & Solyc08g081010.2.1 \\
& TTGCTTATGCATGTTGCTCA & \\
& R: & \\
type 2 Metallothionein (MT2) & ACAACCTCGGCTACTTCGTT & \\
& F: & Solyc09g010800.2.1 \\
& AGCAGCACAACCACTGAGAC & \\
& R: & \\
GBC transporter C family member 2 (ABC1) & F: & \\
& CCATGGCTAGGGCTGTTTAT & Solyc08g006880.2.1 \\
& R: & \\
& GTTCTCCCTTGATGCACCTT & \\
\hline Actin & F: & \\
& TGGTCGGAATGGGACAGAAG & Solyc03g078400.2.1 \\
& R: & \\
\hline
\end{tabular}

\section{Statistical analysis}

Morphological and biochemical measurements were performed with five biological replicates, while gene expression was calculated with three biological replications, each of which was obtained from three technical replications. Data analysis was carried out using SAS 9.1.3 software. The means were compared based on the least significant difference (LSD) test $(p<0.05)$.

\section{Results}

\section{Plant growth, photosynthetic pigments and chlorophyll fluorescence}


Tomato seedling heights were found to be declined by $23.3 \%, 25.4 \%$ and $22.8 \%$ with As, As + cPTIO and As + SNP + cPTIO treatments, respectively, compared to the untreated controls. However, SNP $(100 \mu \mathrm{M})$ application improved plant height by $21.1 \%$ under As stress (Table 2). At $10 \mathrm{mg} / \mathrm{L} \mathrm{As}$, a significant reduction $(39.4 \%)$ was observed in total dry weight of the samples. The application of CPTIO and SNP + CPTIO had no meaningful effect on total dry weight in As-treated plants, however, SNP application increased total dry weight by $47.2 \%$ in As-treated plants (Table 2 ).

Table 2

Effect of $10 \mathrm{mg} / \mathrm{L}$ arsenic (As) alone or in combination with $100 \mu \mathrm{M}$ nitroprusside (SNP) and $200 \mu \mathrm{M} 2-$ (4-carboxyphenyl)-4,4,5,5-tetramethylimidazoline-1-oxyl-3-oxide (cPTIO) on growth, photosynthetic pigments and chlorophyll fluorescence of tomato seedlings

\begin{tabular}{|c|c|c|c|c|c|c|}
\hline \multirow[t]{2}{*}{ Treatments } & \multirow{2}{*}{$\begin{array}{l}\text { Height } \\
\text { (cm) }\end{array}$} & \multirow{2}{*}{$\begin{array}{l}\text { Total Dry } \\
\text { Weight (g) }\end{array}$} & \multicolumn{3}{|c|}{ Photosynthetic pigments $\left(\mathrm{mg} \mathrm{g}^{-1} \mathrm{FW}\right)$} & \multirow[t]{2}{*}{$\mathrm{Fv} / \mathrm{Fm}$} \\
\hline & & & $\begin{array}{l}\text { Chlorophyll } \\
\text { a }\end{array}$ & $\begin{array}{l}\text { Chlorophyll } \\
\text { b }\end{array}$ & Carotenoids & \\
\hline Control & $\begin{array}{l}18.57 \pm \\
0.19 a\end{array}$ & $3.88 \pm 0.23 a$ & $\begin{array}{l}2.14 \pm \\
0.13 a\end{array}$ & $\begin{array}{l}0.83 \pm \\
0.11 \mathrm{a}\end{array}$ & $\begin{array}{l}0.67 \pm \\
0.06 a\end{array}$ & $\begin{array}{l}0.69 \pm \\
0.02 \mathrm{a}\end{array}$ \\
\hline As & $\begin{array}{l}14.25 \pm \\
0.21 \mathrm{c}\end{array}$ & $2.35 \pm 0.17 c$ & $\begin{array}{l}0.83 \pm \\
0.08 c\end{array}$ & $\begin{array}{l}0.33 \pm \\
0.05 b\end{array}$ & $\begin{array}{l}0.22 \pm \\
0.04 d\end{array}$ & $\begin{array}{l}0.43 \pm \\
0.02 \mathrm{~d}\end{array}$ \\
\hline As + SNP & $\begin{array}{l}17.25 \pm \\
0.25 \mathrm{~b}\end{array}$ & $3.46 \pm 0.18 b$ & $\begin{array}{l}1.81 \pm \\
0.17 \mathrm{~b}\end{array}$ & $\begin{array}{l}0.81 \pm \\
0.09 a\end{array}$ & $\begin{array}{l}0.56 \pm \\
0.04 \mathrm{~b}\end{array}$ & $\begin{array}{l}0.62 \pm \\
0.01 b\end{array}$ \\
\hline As + cPTIO & $\begin{array}{l}13.85 \pm \\
0.23 d\end{array}$ & $2.15 \pm 0.24 c$ & $\begin{array}{l}0.71 \pm \\
0.14 c\end{array}$ & $\begin{array}{l}0.36 \pm \\
0.07 \mathrm{~b}\end{array}$ & $\begin{array}{l}0.30 \pm \\
0.05 \mathrm{~d}\end{array}$ & $\begin{array}{l}0.42 \pm \\
0.01 \mathrm{~d}\end{array}$ \\
\hline $\begin{array}{l}\text { As + SNP + } \\
\text { CPTIO }\end{array}$ & $\begin{array}{l}14.33 \pm \\
0.21 \mathrm{c}\end{array}$ & $2.35 \pm 0.14 c$ & $\begin{array}{l}0.79 \pm \\
0.16 \mathrm{c}\end{array}$ & $\begin{array}{l}0.41 \pm \\
0.07 \mathrm{~b}\end{array}$ & $\begin{array}{l}0.42 \pm \\
0.09 \mathrm{c}\end{array}$ & $\begin{array}{l}0.47 \pm \\
0.01 \mathrm{c}\end{array}$ \\
\hline
\end{tabular}

Tomato seedlings exposed to As showed a $61.2 \%$ and $60.2 \%$ decline in chlorophyll $a$ and $b$ contents, respectively, while SNP increased the total chlorophyll $a$ and $b$ content by $118.1 \%$ and $145.5 \%$ respectively in the As-stressed plants. Application of CPTIO and SNP + CPTIO had no significant impact on chlorophyll $a$ and $b$ content in the As-stressed plants (Table 2). As exposure reduced the carotenoids by $67.2 \%$ over the control, however, SNP and SNP + cPTIO significantly improved the carotenoid content by $154.6 \%$ and 90.9 respectively, \% in the seedlings exposed to As stress (Table 2). A remarkable cutback in the chlorophyll fluorescence was observed in As-stressed seedlings over un-treated control. However, the utilization of SNP and SNP + CPTIO increased the chlorophyll fluorescence in As-exposed seedlings while cPTIO alone showed no significant effect (Table 2).

\section{Gas exchange parameters}


The results of gas exchange parameters showed that As toxicity significantly reduced the transpiration rate along with stomatal conductance and net photosynthesis. SNP and SNP + cPTIO markedly improved transpiration rate, stomatal conductance and net photosynthesis in As-exposed tomato seedlings, however, cPTIO alone had no significant effect (Fig. 1A, B, C). Intercellular $\mathrm{CO}_{2}$ concentration significantly enhanced by 60.3, 39.1 and 35.5\% with As + CPTIO, As and As + SNP + cPTIO treated seedlings respectively, over the control, however, As + SNP treatment had no significant effect on intercellular $\mathrm{CO}_{2}$ level (Fig. 1D).

\section{NO and As accumulation}

As exposure elevated the NO concentrations in the roots and leaves by $68.5 \%$ and $92.4 \%$, respectively, over the control. SNP application further increased the NO content both in the roots and leaves of Astreated tomato seedlings, however, CPTIO and SNP + cPTIO significantly reduced the NO content in the roots and leaves (Table 3). After 15 days of exposure to $10 \mathrm{mg} / \mathrm{L} \mathrm{As,} 611 \mu \mathrm{g}$ and $81.9 \mu \mathrm{g}(\mathrm{g} \mathrm{DW})^{-1}$ As accumulated in the tomato roots and shoots, respectively. the application of SNP and CPTIO increased the As concentration by $19.5 \%$ and $9.2 \%$, respectively in As-stressed roots of the seedlings. However, in shoots, SNP treatment markedly reduced the As accumulation in the plants exposed to As toxicity (Table 2). Seedlings exposed to As accumulated average $693 \mu \mathrm{g}(\mathrm{g} \mathrm{DW})^{-1}$ As at whole plant level. Application of cPTIO, SNP and SNP + cPTIO increased the As content to $758 \mu \mathrm{g}, 742 \mu \mathrm{g}$ and $721 \mu \mathrm{g}(\mathrm{g} \mathrm{DW})^{-1}$, respectively, in As-treated seedlings (Table 3). 
Table 3

Effect of $10 \mathrm{mg} / \mathrm{L}$ arsenic (As) alone or in combination with $100 \mu \mathrm{M}$ nitroprusside (SNP) and $200 \mu \mathrm{M} 2$ (4-carboxyphenyl)-4,4,5,5-tetramethylimidazoline-1-oxyl-3-oxide (cPTIO) on the contents of NO, As, proline and total soluble sugars of tomato seedlings

\begin{tabular}{|c|c|c|c|c|c|c|c|}
\hline \multirow[t]{2}{*}{ Treatments } & \multicolumn{2}{|c|}{$\begin{array}{l}\text { NO content } \\
\left(\mu \mathrm{mol} \mathrm{g}{ }^{-1} \mathrm{FW}\right)\end{array}$} & \multicolumn{3}{|c|}{ As content ( $\left.\mu \mathrm{g} \mathrm{g}^{-1} \mathrm{DW}\right)$} & \multirow{2}{*}{$\begin{array}{l}\text { Proline } \\
\text { (nmol g } \\
\text { FW) }\end{array}$} & \multirow[t]{2}{*}{$\begin{array}{l}\text { Total soluble sugars } \\
\left(\mathrm{mg} \mathrm{g}^{-1} \mathrm{DW}\right)\end{array}$} \\
\hline & Root & Leaf & Root & Shoot & $\begin{array}{l}\text { Whole } \\
\text { plant }\end{array}$ & & \\
\hline Control & $\begin{array}{l}2.16 \pm \\
0.19^{d}\end{array}$ & $\begin{array}{l}2.24 \pm \\
0.16^{d}\end{array}$ & nd & nd & nd & $1.72 \pm 0.13^{d}$ & $17.65 \pm 0.42^{b}$ \\
\hline As & $\begin{array}{l}3.64 \pm \\
0.15^{b}\end{array}$ & $\begin{array}{l}4.31 \pm \\
0.17^{b}\end{array}$ & $\begin{array}{l}611 \pm \\
22^{\mathrm{c}}\end{array}$ & $\begin{array}{l}81.9 \pm \\
5.9^{\mathrm{ab}}\end{array}$ & $\begin{array}{l}693 \pm \\
18^{\mathrm{b}}\end{array}$ & $6.60 \pm 0.31^{b}$ & $13.16 \pm 0.34^{c}$ \\
\hline As + SNP & $\begin{array}{l}5.15 \pm \\
0.23^{\mathrm{a}}\end{array}$ & $\begin{array}{l}5.29 \pm \\
0.31^{\mathrm{a}}\end{array}$ & $\begin{array}{l}730 \pm \\
26^{a}\end{array}$ & $\begin{array}{l}12.6 \pm \\
1.6^{c}\end{array}$ & $\begin{array}{l}742 \pm \\
27^{a}\end{array}$ & $3.82 \pm 0.25^{c}$ & $19.10 \pm 0.36^{a}$ \\
\hline As + cPTIO & $\begin{array}{l}1.94 \pm \\
0.17^{d}\end{array}$ & $\begin{array}{l}2.21 \pm \\
0.20^{d}\end{array}$ & $\begin{array}{l}667 \pm \\
19^{b}\end{array}$ & $\begin{array}{l}91.1 \pm \\
7.1^{\mathrm{a}}\end{array}$ & $\begin{array}{l}758 \pm \\
22^{a}\end{array}$ & $8.46 \pm 0.27^{a}$ & $10.45 \pm 0.26^{d}$ \\
\hline $\begin{array}{l}\text { As + SNP + } \\
\text { CPTIO }\end{array}$ & $\begin{array}{l}2.55 \pm \\
0.19^{c}\end{array}$ & $\begin{array}{l}2.66 \pm \\
0.17^{c}\end{array}$ & $\begin{array}{l}643 \pm \\
16^{\mathrm{bc}}\end{array}$ & $\begin{array}{l}77.9 \pm \\
7.3^{b}\end{array}$ & $\begin{array}{l}721 \pm \\
22^{\mathrm{ab}}\end{array}$ & $8.27 \pm 0.31^{a}$ & $12.89 \pm 0.30^{\mathrm{C}}$ \\
\hline
\end{tabular}

\section{Proline and total soluble sugars content}

Leaf proline content raised by 4.9-, 4.8-, 3.8- and 2.2-fold in As + CPTIO, As + SNP + cPTIO, As and As + SNP treatments, respectively over the control (Table 3). As toxicity $(10 \mathrm{mg} / \mathrm{L})$ caused a significant turn down in the content of the total soluble sugars in the leaves of tomato seedlings over the non-treated seedlings. Application of SNP boosted the total soluble sugar amounts in the leaves of As-stressed seedlings however, CPTIO supplementation lowered the total soluble sugar in the As-exposed seedlings (Table 3).

\section{Proline and chlorophyll metabolism}

The activities of enzymes involved in the proline (proline dehydrogenase (PDH) and 1-pyrroline-5carboxylate synthetase (P5CS)) and chlorophyll (( $\delta$-aminolevulinic acid dehydratase ( $\delta$-ALAD) and chlorophyllase (Chlase)) metabolism were also evaluated. The data showed that As toxicity caused a significant decrease in the PDH activity compared to the unstressed seedlings. SNP increased the PDH activity by $38.2 \%$, however, CPTIO declined the PDH activity by $21.1 \%$. in the As-stressed seedlings. 
Simultaneous supplementation of the SNP and CPTIO represented no meaningful effect on PDH activity in the As-exposed seedlings (Fig. 2A). P5CS activity significantly increased in the seedlings supplemented with As, As + SNP, As + cPTIO and As + SNP + cPTIO towards control, so that the highest and lowest P5CS activity were recorded in As + CPTIO and As + SNP treatments by 4.4 and 2.3-fold increase respectively over the control (Fig. 2B).

The combination of As and SNP significantly enhanced $\delta$-ALAD activity, which was found $3.5 \%$ higher than the control. However, As, As + CPTIO and As + SNP + CPTIO treatments significantly reduced $\delta-A L A D$ activity and the lowest activity was observed in the As + CPTIO treatment (Fig. 2C). As toxicity remarkably induced the activity of Chlase enzyme in tomato leaves compared to the control. The application of SNP decreased the activity of Chlase, while the use of CPTIO further increased the activity of Chlase enzyme in the As-stressed seedlings, however, combination of SNP and CPTIO had no significant synergistic effect on the Chlase activity (Fig. 2D).

\section{ROS and MG metabolism}

Toxic As significantly oxidized the lipids attributed to the MDA and $\mathrm{H}_{2} \mathrm{O}_{2}$ increase by 3- and 2.6-fold respectively relative to the untreated control seedlings. SNP significantly lowered the MDA and $\mathrm{H}_{2} \mathrm{O}_{2}$ content, while CPTIO increased those in the As-stressed plants. Combined SNP and CPTIO had no statistically significant change on the MDA and $\mathrm{H}_{2} \mathrm{O}_{2}$ contents of the As-stressed seedlings (Fig. $3 \mathrm{~A}, \mathrm{~B}$ ).

Application of As and As + SNP treatments up-regulated the CAT (by 1.8- and 2.4-fold) and APX (by 1.9and 2.5 -fold) activities over the control. As + cPTIO and As + SNP + cPTIO treatments did not affect ( $p>$ 0.05) the activity of CAT and APX compared to the control (Fig. 3C, D). A 43.7\% increase in the SOD activity was observed in the seedlings exposed to As toxicity compared to the untreated seedlings. SNP increased the activity of SOD by $12.9 \%$, in the As-stressed seedlings, however, CPTIO and SNP + CPTIO treatments lead reductions (Fig. 3E). As treatment significantly induced the GR activity over the control. SNP application up-regulated the GR activity in the As-stressed tomatoes, however, CPTIO and SNP + CPTIO showed a negative effect on GR activity, which reduced by $47.7 \%$ and $22.7 \%$, respectively (Fig. 3F).

Our data showed that the As toxicity caused a compelling rise in the MG content of tomato leaves compared to the control. SNP decreased the MG content in the As-stressed seedlings, while CPTIO and SNP + cPTIO treatments had an additive synergistic effect (Fig. 4A). As stress also upregulated the active states of Gly I and Gly II enzymes compared to the untreated seedlings. SNP treatment upregulated the activity of Gly I and Gly II enzymes by $23.1 \%$ and $35 \%$ respectively in the stressed plants. CPTIO and SNP + CPTIO treatments remarkably declined the Gly I activity in As-exposed seedlings, yet did not show a significant effect on Gly II activity (Fig. 4B).

\section{Phytochelatins and AsA-GSH cycle}


Data showed that the root and leaf phytoclatin contents enhanced by $53.4 \%$ and $108.3 \%$ respectively towards $10 \mathrm{mg} / \mathrm{L}$ of As toxicity, over the untreated seedlings. SNP application notably enhanced the phytoclatin concentrations in the roots and leaves of the stressed seedlings, however, CPTIO and SNP + CPTIO treatments significantly declined the concentrations in roots and leaves (Fig. 4C).

As stress did not impact the GSH quantity, however, SNP caused a boost in the content. CPTIO alone had no remarkable effect in the As-treated seedlings, yet, CPTIO along with SNP elevated the GSH levels (Fig. 4D). A 52.2\% increase in the GSSG content was recorded under As toxicity over the control, while SNP supplementation caused a further increase in GSSG content by $7.3 \%$. However, CPTIO and SNP + cPTIO treatments significantly lowered the GSSG (Fig. 4D). As toxicity resulted in a momentous decline in the AsA content over the control, however, exogenous AsA content was higher by SNP in As-treated seedlings. Exogenous CPTIO and SNP + CPTIO had no remarkable effect on the leaves' AsA content under toxicity (Fig. 4E). As toxicity also elevated the DHA content in the leaves compared to the control, however, the CPTIO alone showed an additive effect on the DHA content. SNP and SNP + CPTIO treatments reduced the DHA content in As-stressed seedlings, which SNP was more effective in declining DHA (Fig. 4E). As toxicity significantly reduced the related ratios of GSH/GSSG and AsA/DHA by $32.2 \%$ and $73.1 \%$, respectively, compared with unstressed seedlings. SNP, cPTIO and SNP + CPTIO improved the GSH/GSSG ratio and the highest increase was recorded under SNP treatment under stress. The AsA/DHA ratio significantly enhanced with SNP treatment in As-stressed seedlings, however, CPTIO treatment reduced the AsA/DHA ratio (Fig. 4F).

\section{As sequestration}

The expression of $P C S, G S H 1, M T 2$ and $A B C 1$ genes involved in the synthesis of PCs, GSH, metallothionein and $\mathrm{ABC}$ transporter was analyzed here to determine the role of $\mathrm{NO}$ in the regulation of the gene expression web involved in the As detoxification. Expression pattern of the PCS and GSH1 in the roots and leaves of seedlings treated with $10 \mathrm{mg} / \mathrm{L}$ As showed a significant increase over the control, that the SNP lead an up-regulation in the expression of both PCS and GSH1. However, CPTIO and SNP + cPTIO treatments did not have a powerful effect on the expression levels (except for expression of GSH1 gene in roots which decreased under CPTIO alone) (Fig. 5A, B). Transcription levels of MT2 and $A B C 1$ on the other hand, also upregulated by approximately $2.3 / 2.8$ - and 1.8/2.4-fold in the roots/leaves. The SNP elevated the expression of $M T 2$ and $A B C 1$ genes in the roots of As-exposed seedlings, while no significant effect on their expression in leaves was detected. However, CPTIO and SNP + CPTIO down-regulated the expression of $A B C 1$ in the leaves and also MT2 both in the roots and leaves (Fig. 5B, C).

\section{Discussion}

Arsenic, as one of the most toxic metalloids, changes the genome-wide chromatin dynamics and/or transcriptome patterns of the key genes in plants. Beyond showing injurious effects on the growth and yield penalties, due to the As accumulation in the edible parts of the plants, biomagnification in the 
contaminated food results in serious diseases as leukemia, diabetes, skin cancer and cardiovascular problems when recommended threshold levels are chronically exceeded by daily consumption [36, 71]. Therefore, the use of appropriate and efficient methods to reduce the up-take and/or excessive accumulation of As in plants, especially in the edible organs, not only improve the plant growth and yield but also secure the public health. Tomato crop production and /or cultivation of different varieties or genetic backgrounds has long been practiced which is almost equal to 60 million tones today, indicates the importance of this fruit consumption at global scale. Several other works in the literature stated that As showed negative effects on growth and reduced the plant height along with biomass production on tomato [11], rice [46] and faba bean [2]. Ghiani et al. [23] also indicated that As arrested the cell division cycle by inhibiting the DNA synthesis process and, as a result, reduced plant growth. Mousavi et al. [46] reported that toxic As reduced the development and the yield of rice by generating an oxidative burst as well as reducing the absorption and translocation of iron to the shoots. However molecular interactions of As orchestrated by a great amount of biochemical processes and stress signalling pathways of tomato plants remain largely unknown up to date. The application of SNP $(100 \mu \mathrm{M})$ as a NO donor here restored growth and improved plant biomass under As toxicity $(10 \mathrm{mg} / \mathrm{L})$, indicating the role of $\mathrm{NO}$ in improving plant tolerance against As. Similar results of the positive effect of SNP which increasing the resilience of plants against various heavy metal toxicity have previously been noted $[2,51,59]$. Novikova et al. [49] also showed that optimal concentrations of NO elevated cell number in S-phase of cell division cycle and induced G1/S transition by upgrading the expression of CYCD3:1 and CDKA:1 genes. Namdjoyan and Kermanian [48] further reported that SNP improved plant tolerance under As phytotoxicity by elaborating the activity of antioxidant enzymes and reducing oxidative stress as well as As translocation from roots to the shoot. However, the CPTIO supply alone or in combination with SNP intensified the effect of As toxicity on tomato and reversed the SNP amelioration on plant growth improvement, according to the results of Kaya et al. [38] and Phang et al. [51]. Thus, CPTIO inhibition on the protective role of SNP under As stress confirms the performance of NO in improving plant tolerance and growth recovery.

The results showed that As reduced the photosynthetic pigment intactness and the Fv/Fm ratio linked with the maximum potential quantum efficiency of Photosystem II which was associated with the decreased $\delta$-ALAD activity and increased Chlase activity. These enzymes are involved in the chlorophyll biosynthesis and degradation, respectively. Accumulation of As in plant shoots has also recently been reported to be disrupted the vital physiological processes including chloroplast morphology and plastid quantity, PSII photochemistry, tetrapyrrole biosynthesis and consequently reduced photo-assimilation and ATP biosynthesis [37, 50]. Amplified and accelerated accumulation of radicals/ROS and subsequent induction of the oxidative stress under As phytotoxicity is another factor that provoke damage to the photosynthetic apparatus by inducing Chlase activity and degrading chlorophylls within the thylakoid membrane [56]. In this context, our data indicated that the SNP application exhibited a higher $\delta$-ALAD activity and lower Chlase activity, thus developed photosynthetic pigment intactness under As toxicity. Similar notions which showing improved photosynthetic pigments content secured by SNP under As [2, 48], $\mathrm{Cu}$ [45] and $\mathrm{Cd}$ [65] toxicity have also been reported. 
NO individually has been shown to increase the synthesis of small molecular weight protective molecules, photosynthetic pigments, and maintain active nutrient uptake which results in improved photo-assimilate production which is the major focus in restoring plant growth under As toxicity [19]. Our results in this regard showed that the supplemented SNP improved the $\mathrm{CO}_{2}$ fixation in the Calvin cycle and net photosynthetic performance by improving the gas exchange parameters: transpiration rate through stomatal conductance. The up-grade occurred in the SNP-induced gas exchange parameters under As [2], Cd [4] and salinity [20] stress have also been reported in other works. Ahmad et al. [2] recently indicated that the SNP acts as a stomatal conductance regulator of the As-stressed plants by energizing the cellular antioxidant system and increasing the water status. Thus, our findings set a consisting stage that NO, by boosting the activity of $\delta-A L A D$ and lowering the Chlase efficiency, reestablished the intactness of the tomato photosynthetic pigments and improved the maximum energy efficiency (energy stored per mole of oxygen) of the the photosynthetic apparatus in As-stressed seedlings. CPTIO alone or in combination with SNP blocked the protective role of the SNP on the chlorophyll content and the integrity of the photosynthetic apparatus, since CPTIO acts as a NO scavenger, indicating the reviving role of $\mathrm{NO}$ in the As-exposed seedlings.

As stress elevated the NO accumulation in the roots and shoots of tomato seedlings, according to the results obtained by Ahmad et al. [2]. Increasing the endogenous NO content under As stress could indicate the major role of $\mathrm{NO}$ as a signal molecule in regulating overall plant physiological processes under stressful conditions. Thus, SNP application here indeed lead to a greater multiplication of NO in the roots and leaves of As-stressed tomato seedlings, which is compatible with the results reported by Kaya et al. [38] and Ahmad et al. [2]. Therefore, we can conclude that further increase in endogenous NO could effectively reduce ROS levels and alleviate oxidative damage in As-exposed seedlings. Due to the negative effects of $\mathrm{NO}$ at high concentrations [66], maintaining a balanced level of $\mathrm{NO}$ is essential to guarantee a well-balanced tolerance. In our work, the SNP-induced NO content did not reach up to the toxic levels to exert irreversible adverse effects on the general physiological pathways of the As-stressed seedlings. CPTIO alone or in combination with SNP remarkably reduced the NO content, which confirms the blocking the protective role of SNP was due to a decline in the endogenous NO levels. Our data also showed that although SNP utilization increased the As content at whole plant level, seedlings treated with the SNP accumulated less As in the shoot, reaffirms that NO reduced the As translocation to the shoots by immobilizing the excessive As in tomato roots. Similarly, the immobilization of $\mathrm{Cu}$ in the Nasturtium officinale R.Br. roots by SNP has been shown by Namdjoyan and Kermanian [48]. It was also shown that the NO improved the plant tolerance to $\mathrm{Cd}$ toxicity by triggering the synthesis of hemicellulose and pectin in the root cell wall and enhanced the accumulation of $\mathrm{Cd}$ root cell walls in the and thus reducing $\mathrm{Cd}$ translocation to the leaves [67]. Therefore, by immobilizing the As in the roots, SNP prevented the As translocation to the more fragile organs and, consequently, hindered particularly the possible stunted photosynthetic yield.

Proline accumulation under abiotic stress sustain cellular osmolarity, ROS scavenging, improving protein functions and redox homeostasis. Here, we found that the As stress up-regulated P5CS activity and 
down-regulated the PDH activity, thus gave rise to proline accumulation in tomato leaves, which might be explained by the As-born putative water stress as documented by Ahmad et al. [2]. Mostofa et al. [45] further indicated that the decline in the RWC content induced the proline synthesis in the plants under heavy metal toxicity. Contrarily, we detected that SNP application decreased the P5CS activity while increasing PDH activity, thereby halted the proline synthesis and/or accumulation in the As-stressed tomato seedlings. Less proline quantities induced by the SNP application may indicate a partial relief here. Parallel results regarding reductions in the SNP-mediated proline contents under $\mathrm{Cu}$ [45] and $\mathrm{Ni}$ toxicity [39] have been reported as well. Hence, SNP-induced proline metabolism was reversed by the use of CPTIO, which confirms the major regulation role of NO in the proline metabolism.

Levels of joint MDA, MG and $\mathrm{H}_{2} \mathrm{O}_{2}$ indicate the damage index caused by the oxidative stress under unfavorable conditions. The results here showed that the As stress lead to an occurred leaf MDA and $\mathrm{H}_{2} \mathrm{O}_{2}$ increase in tomato seedlings, which points out the induction of the oxidative stress, resulting in the oxidation of the bi-layer membrane lipids. Similar results of MDA and $\mathrm{H}_{2} \mathrm{O}_{2}$ accumulation in rice [46] and bean [2] under As toxicity have also been reported. ROS provokes major injuries to cellular metabolism that, by inducing the Haber-Weiss reaction, which results formation of the hydroxyl radicals as well as the peroxidation of pigments made from lipids, thus impairs the membrane function and permeability [44]. Sharma [54] also indicated that As, reduces the antioxidant enzyme activities and induces the oxidative stress in plants by binding directly to the thiol groups. Additionally, Talukdar (2013) reported upregulated gene expression of the antioxidant system elements CAT, APX and SOD, reduces the oxidative stress lead by excessive As toxicity. Correspondingly, SNP application here markedly improved the activity of CAT, SOD, APX and GR in the As-exposed seedlings, which was found in accordance with the data reported by Ahmad et al. [2], Hasanuzzaman and Fujita [29] and Namdjoyana and Kermanian [48]. Graziano and Lamattina [25] also showed that the NO increases the biosynthesis of APX and CAT enzymes by enhancing the iron availability for plants. NO in this manner, has been shown to play a critical role in plant tolerance against heavy metal toxicity by promoting the functionality of the antioxidants and by cross-talking with other key molecules in the defense mechanisms, including ethylene, salicylic acid and jasmonic acid signalling $[3,38,56]$. Harmonizing the activity of enzymes in the AsA-GSH cycle by NO on the other hand greatly helps to maintain redox homeostasis, $\mathrm{H}_{2} \mathrm{O}_{2}$ reduction and thus protect the embedded protein-pigment complexes in the photosynthetic machinery [7]. Therefore, balancing the GR and APX activity and regulating the GSH and AsA dynamics would limit conformational changes of the proteins thereby cell functioning under As toxicity by reducing the toxic hydroxyl radical levels. Here in our work, the SNP application promoted the cellular GSH and AsA amounts and, as a result, improved the ratios of GSH/GSSG and AsA/DHA, which was consistent with the recent results obtained in faba bean [2] and wheat [29] grown under As toxicity. Farnese et al. [18] also stated that the NO activates the antioxidant machinery and increases the GSH levels under by triggering the As-response signaling pathways. Therefore, we conclude that the SNP reduced the free radical genesis and lipid per-oxidation by orchestrating the antioxidant enzyme activities and the redox status of the AsA-GSH cycle, thereby reorganized the tomato growth under As toxicity. CPTIO supplementation which completely inverted the 
effects of SNP on the antioxidant defense system and MDA and ROS levels in As-stressed seedlings, indicates the role of NO in regulating the plant's antioxidant system under unfavorable conditions.

Mutagenic and cytogenetic impacts of As-induced MG could have detrimental outcomes on the proteins and thus the function of the biochemical processes that may even lead to cell death [69]. Overexpression of the two enzymes (Gly I and Gly II) involved in the MG scavenge, has been shown to effectively reduce MG levels under abiotic stress $[53,60]$. As for the stress factor here in our work, As up-regulated the activity of Gly I and II in tomato leaves, yet, MG levels were also elevated. This indicates that the tomato glyoxalase system was insufficient in sweeping MG amounts induced by exposed As toxicity. Same theory, have also been argued in the wheat [29] and bean [2]. Our SNP application declined the MG level in the As-stressed plants by further increasing the activity of Gly I and II enzymes, indicating the effectiveness of the NO on the glyoxalase system and capability in reducing the toxic MG. Ahmad et al. [2] also indicated that the SNP supplementation reduced the MG level and thus improved the growth of plant, by improving the glyoxalase system. On the other hand, we observed increased levels of MG by CPTIO and SNP + CPTIO application which confirms the protective role of NO on the glyoxalase complex and $M G$ accumulation under As phyto-toxicity. However, further research at the molecular level is needed to elucidate the precise role of NO in regulating the glyoxalase system under As toxicity.

PCs have an outstanding role in the prevention of the phytotoxicity caused by heavy metals by chelating the metal ions [27]. Our results indicated that PCs accumulated both in the roots and leaves of the Asstressed tomato seedlings, which were further elevated with SNP supplementation. Souri et al. [61] stated that the SNP improves the tolerance of As-stressed Isatis cappadocica plants by coordinating the protein and non-protein thiol contents. It has also been reported that the plants were capable of accumulating higher As concentrations in their shoots by PCs complexation [62]. SNP here up-regulated the PCS and GSH1 gene transcript abundances in the roots and leaves of the As-stressed tomato seedlings, which was consistent with the higher contents of PCs and GSH as expected. Hasan et al. [28] reported that the upregulating the expression of genes involved in heavy metal sequestration plays a vital role in improving a rapid plant tolerance under heavy metal phyto-toxicity. Our results corroborating with this notion that the expression levels of $G S H 1, P C S, A B C 1$ and $M T 2$ genes in tomato roots was higher than that of the leaves. Thus, NO here immobilized the As in the roots and scaled down the quantity translocated to the shoots, by up-regulating the genes involved in the As sequestration (GSH1, PCS, ABC1 and MT2) and enhancing the GSH and PCs contents, which could persuasively protect the sensitive photosynthetic organs from As toxicity. However, CPTIO inhibited the effect of NO on the expression of GSH1, PCS, ABC1 and MT2 genes, proving the response designer role of NO in As sequestration particularly in the roots.

\section{Conclusion}

The ability to detoxify and/or sequester toxic contaminants such as As in plants has been instrumental in plant survival in the As-polluted environments. Our data showed that the external SNP application accumulated the endogenous NO content of As stressed tomato seedlings. Furthermore, SNP displayed protective and complex effects on the metabolism of photosynthetic pigments and proline, gas exchange, 
ROS and MG scavenging, antioxidant redox status, biosynthesis of PCs and GSH, and consequently As sequestration in the vacuoles. Although SNP boosted the As accumulation in the roots, the accumulation of As in the shoots decreased, indicating the NO blockage in the As translocation. On the other hand, CPTIO treatment as an NO scavenger reversed the protective effects of SNP in As-exposed seedlings, which strongly confirms the key role of NO in As phyto-toxicity tolerance. The findings here in this work could provide a cellular interaction scheme and molecular insights to develop potent strategies for healthy food farming, particularly in the As-polluted marginal areas. Yet, further research at the molecular level is needed to support the role of $\mathrm{NO}$ in As detoxification as well as to identify subsequent signaling cascades.

\section{Declarations}

\section{Authors' contributions}

Conceptualization and Methodology, A.G., C.W.; Validation and Investigation, A.G., L.P.; Analysis, A.G., C.W.; Resources, L.P., N.R.; Writing original, A.G; Review and editing, N.P. All authors have read and agreed to the published version of the manuscript.

\section{Ethics approval and consent to participate}

It is not applicable to this study.

\section{Consent for publication}

Not applicable.

\section{Availability of data and materials}

All data generated from the study and reported in the manuscript are included in the article. Further data sets are available from the corresponding author upon request

\section{Competing interests}

The authors declare that they have no competing interests.

\section{Funding}

Not applicable 


\section{References}

1. Aebi H. Catalase in vitro, in: Colowick, S., Kaplan, N. (Eds.), Methods in Enzymology. Elsevier, Florida, 1984; pp. 121-126.

2. Ahmad P, Alam P, Balawi TH, Altalayan FH, Ahanger MA, Ashraf M. Sodium nitroprusside (SNP) improves tolerance to arsenic (As) toxicity in Vicia faba through the modifications of biochemical attributes, antioxidants, ascorbate-glutathione cycle and glyoxalase cycle. Chemosphere. 2020;244:125480.

3. Ahmad P, Ahanger MA, Nasser Alyemeni M, Wijaya L, Alam P, Ashraf M. Mitigation of sodium chloride toxicity in Solanum lycopersicum by supplementation of jasmonic acid and nitric oxide. J Plant Interact. 2018;3:64-72.

4. Ahmad P, Ahanger MA, Alyemeni MN, Wijaya L, Alam P. Exogenous application of nitric oxide modulates osmolyte metabolism, antioxidants, enzymes of ascorbate-glutathione cycle and promotes growth under cadmium stress in tomato. Protoplasma. 2018;255:79-93.

5. Ahmad P, Jaleel CA, Salem MA, Nabi G, Sharma S. Roles of enzymatic and nonenzymatic antioxidants in plants during abiotic stress. Crit. Rev. Biotechnol. 2010;30:161-175.

6. Alavi SMN, Arvin MJ, Kalantari KM. Salicylic acid and nitric oxide alleviate osmotic stress in wheat (Triticum aestivum) seedlings. J Plant Interact. 2014;9:683-688.

7. Alyemeni MN, Ahanger MA, Wijaya L, Alam P, Bhardwaj R, Ahmad P. Selenium mitigates cadmiuminduced oxidative stress in tomato (Solanum lycopersicum) plants by modulating chlorophyll fluorescence, osmolyte accumulation, and antioxidant system. Protoplasma. 2018;255(2):459-469.

8. Barringer JL, Reilly PA. Arsenic in groundwater: A summary of sources and the biogeochemical and hydrogeologic factors affecting arsenic occurrence and mobility, Current perspectives in contaminant hydrology and water resources sustainability. INTECH Open Access Publisher. 2013.

9. Bates LS, Waldren RP, Teare ID. Rapid determination of free proline for water-stress studies. Plant Soil. 1973;39:205-207.

10. Bradford MM. A rapid and sensitive method for the quantification of microgram quantities of protein utilizing the principle of protein-dye binding. Anal Biochem. 1976;72:248-254.

11. Carbonell-Barrachina AA, Burló F, Burgos-Hernández A, López E, Mataix J. The influence of arsenite concentration on arsenic accumulation in tomato and bean plants, Sci Hortic. 1997;71(3-4):167176.

12. Charest C, Phan CT. Cold-acclimation of wheat (Triticum Aestivum) - properties of enzymes involved in proline metabolism. Physiol Plant. 1990;80:159-168.

13. Costa ML, Civello PM, Chaves AR, Martínez GA. Effect of ethephon and 6-benzylaminopurine on chlorophyll degrading enzymes and a peroxidase-linked chlorophyll bleaching during post-harvest senescence of broccoli (Brassica oleracea) at 20 C. Postharvest Biol Technol. 2005:35(2):191-9.

14. De Vos RCH, Vonk MJ, Vooijs R, Schat H. Glutathione depletion due to copper-induced phytochelatin synthesis causes oxidative stress in Silene cucubalus. Plant Physiol. 1992;981:853-858. 
15. Dhindsa RS, Matowe W. Drought tolerance in two mosses: correlated with enzymatic defence against lipid peroxidation. J Exp Bot. 1981;32:79-91.

16. Dong Y, Xu L, Wang Q, Fan Z, Kong J, Bai X. Effects of exogenous nitric oxide on photosynthesis, antioxidative ability, and mineral element contents of perennial ryegrass under copper stress. J Plant Interact. 2014;9:402-411.

17. Dutilleul C, Driscoll S, Cornic G, De Paepe R, Foyer CH, Noctor G. Functional mitochondrial complex I is required by tobacco leaves for optimal photosynthetic performance in photorespiratory conditions and during transients. Plant Physiol. 2003;131:264-275.

18. Farnese FS, de Oliveira JA, Gusman GS, Leão GA, Ribeiro C, Siman LI, Cambraia J. Plant Responses to Arsenic: the Role of Nitric Oxide. Water Air Soil Pollut. 2013;224:1660.

19. Farnese FS, de Oliveira JA, Paiva EAS, Menezes-Silva PE, da Silva AA, Campos FV, Ribeiro C. The involvement of nitric oxide in integration of plant physiological and ultrastructural adjustments in response to arsenic. Front Plant Sci. 2017;8:516.

20. Fatma M, Masood A, Per TS, Khan NA. Nitric oxide alleviates salt stress inhibited photosynthetic performance by interacting with sulfur assimilation in mustard. Front Plant Sci. 2016;7:521.

21. Foyer CH, Noctor G. Ascorbate and glutathione: the heart of the redox hub. Plant Physiol. 2011;155:218.

22. Garg N, Singla P. Arsenic toxicity in crop plants: physiological effects and tolerance mechanisms. Environ Chem Lett. 2011;9:303-321.

23. Ghiani A, Fumagalli P, Nguyen Van T, Gentili R, Citterio S. The Combined Toxic and Genotoxic Effects of Cd and As to Plant Bioindicator Trifolium repens PLOS ONE 2014;9:e99239.

24. Gill RA, Ali B, Islam F, Farooq MA, Gill MB, Mwamba TM, Zhou W. Physiological and molecular analyses of black and yellow seeded Brassica napus regulated by 5-aminolivulinic acid under chromium stress. Plant Physiol Biochem. 2015;94:130-143.

25. Graziano M, Lamattina L. Nitric oxide accumulation is required for molecular and physiological responses to iron deficiency in tomato roots. Plant J. 2007;52:949-960.

26. Groß F, Durner J, Gaupels F. Nitric oxide, antioxidants and prooxidants in plant defence responses. Front Plant Sci. 2013;4:419.

27. Hall JL. Cellular mechanisms for heavy metal detoxification and tolerance. J Exp Bot. 2002;53:1-11.

28. Hasan MK, Ahammed GJ, Yin L, Shi K, Xia X, Zhou Y, Yu J, Zhou J. Melatonin mitigates cadmium phytotoxicity through modulation of phytochelatins biosynthesis, vacuolar sequestration, and antioxidant potential in Solanum lycopersicum Front Plant Sci. 2015;6:601.

29. Hasanuzzaman M, Fujita M. Exogenous sodium nitroprusside alleviates arsenic-induced oxidative stress in wheat (Triticum aestivum) seedlings by enhancing antioxidant defense and glyoxalase system. Ecotoxicology. 2013;22(3):584-96.

30. Hasanuzzaman M, Hossain MA, Fujita M. Nitric oxide modulates antioxidant defense and methylglyoxal detoxification system and reduces salinity induced damage in wheat seedling. Plant 
Biotecnol Rep. 2011;5:353-365

31. Heath RL, Packer L. Photoperoxidation in isolated chloroplasts. I. Kinetics and stoichiometry of fatty acid peroxidation. Arch Biochem Biophys. 1968;125:189.

32. Heikens A, Panaullah GM, Meharg AA. Arsenic Behaviour from Groundwater and Soil to Crops: Impacts on Agriculture and Food Safety, Reviews of Environmental Contamination and Toxicology. Springer New York. 2007;43-87.

33. Hermes V, Dall'Asta P, Amaral F, Anacleto K, Arisi A. The regulation of transcription of genes related to oxidative stress and glutathione synthesis in Zea mays leaves by nitric oxide. Biol Plant. 2013;57:620-626.

34. Hu X. NO-mediated hypersensitive responses of rice suspension cultures induced by incompatible elicitor. Chinese Sci Bull. 2003;48:358.

35. Jain M, Gadre R. Inhibition of chlorophyll biosynthesis by mercury in excised etiolated maize leaf segments during greening: effect of 2-oxoglutarate. Indian J Exp Biol. 2004;42:419-

36. Ji R, Zhou L, Liu J, Wang Y, Yang L, Zheng Q, Zhang C, Zhang B, Ge H, Yang Y, Zhao F, Luan S, Lan W. Calcium-dependent protein kinase CPK31 interacts with arsenic transporter AtNIP1;1 and regulates arsenite uptake in Arabidopsis thaliana. PLOS ONE 2017;12:e0173681.

37. Jung HI, Kong MS, Lee BR, Kim TH, Chae MJ, Lee EJ, Jung GB, Lee CH, Sung JK, Kim YH. Exogenous glutathione increases arsenic translocation into shoots and alleviates arsenic-induced oxidative stress by sustaining ascorbate- glutathione homeostasis in rice seedlings. Front Plant Sci. 2019;10:1089.

38. Kaya C, Ashraf M, Alyemeni MN, Corpas FJ, Ahmad P. Salicylic acid-induced nitric oxide enhances arsenic toxicity tolerance in maize plants by upregulating the ascorbate-glutathione cycle and glyoxalase system. J Hazard Mater. 2020:399:123020.

39. Kazemi N, Khavari-Nejad RA, Fahimi H, Saadatmand S, Nejad-Sattari T. Effects of exogenous salicylic acid and nitric oxide on lipid peroxidation and antioxidant enzyme activities in leaves of Brassica napus under nickel stress. Sci Hortic. 2010;126:402-407

40. Kumar V, Yadav SK. Proline and betaine provide protection to antioxidant and methylglyoxal detoxification systems during cold stress in Camellia sinensis (L.) O. Kuntze. Acta Physiol Plant 2009;31:261-269.

41. Lichtenthaler HK. Chlorophylls and carotenoids: pigments of photosynthetic biomembranes. Method Enzymol. 1987;148:350-382.

42. Livak KJ, Schmittgen TD. Analysis of relative gene expression data using real-time quantitative PCR and the $2^{-\triangle \Delta C T}$ Methods. 2001;25:402-408.

43. Meharg AA, Hartley-Whitaker J. Arsenic uptake and metabolism in arsenic resistant and nonresistant plant species. New Phytol. 2002;154:29-43.

44. Mittler R, Finka A, Goloubinoff P. How do plants feel the heat? Trends Biochem Sci. 2012;37:118125. 
45. Mostofa MG, Seraj ZI, Fujita M. Exogenous sodium nitroprusside and glutathione alleviate copper toxicity by reducing copper uptake and oxidative damage in rice (Oryza sativa) seedlings. Protoplasma. 2014;251(6):1373-86.

46. Mousavi SR, Niknejad Y, Fallah H, Barari Tari D. Methyl jasmonate alleviates arsenic toxicity in rice. Plant Cell Rep. 2020;39:1041-1060.

47. Nakano Y, Asada K. Hydrogen peroxide is scavenged by ascorbate-specific peroxidase in spinach chloroplasts. Plant Cell Physiol. 1981;22:867-880.

48. Namdjoyan S, Kermanian H. Exogenous nitric oxide (as sodium nitroprusside) ameliorates arsenicinduced oxidative stress in watercress (Nasturtium officinale Br.) plants. Sci Hortic. 2013;161:350356.

49. Novikova GV, Mur LAJ, Nosov AV, Fomenkov AA, Mironov KS, Mamaeva AS, Shilov ES, Rakitin VY, Hall MA. Nitric oxide has a concentration-dependent effect on the cell cycle acting via EIN2 in Arabidopsis thaliana cultured cells. Front Physiol. 2017;8:142.

50. Patel A, Tiwari S, Prasad SM. Toxicity assessment of arsenate and arsenite on growth, chlorophyll a fluorescence and antioxidant machinery in Nostoc muscorum. Ecotoxicol Environ Saf. 2018;157:369-379.

51. Phang IC, Leung DWM, Taylor HH, Burritt DJ. The protective effect of sodium nitroprusside (SNP) treatment on Arabidopsis thaliana seedlings exposed to toxic level of $\mathrm{Pb}$ is not linked to avoidance of $\mathrm{Pb}$ uptake, Ecotoxicol Environ Saf. 2011;74(5):1310-1315.

52. Principato GB, Rosi G, Talesa V, Govannini E, Uolila L. Purification and characterization of two forms of glyoxalase II from rat liver and brain of Wistar rats. Biochem Biophys Acta. 1987;911:349-355.

53. Saxena M, Deb Roy S, Singla-Pareek S-L, Sopory SK, Bhalla-Sarin N. Overexpression of the glyoxalase II gene leads to enhanced salinity tolerance in Brassica juncea. The Open Plant Sci J. 2011;5:23-28

54. Sharma I. Arsenic induced oxidative stress in plants. Biologia 2012;67(3):447-453.

55. Shi H, Qian Y, Tan DX, Reiter RJ, He C. Melatonin induces the transcripts of CBF/DREB1s and their involvement in both abiotic and biotic stresses in Arabidopsis. J Pineal Res. 2015;59:334-342.

56. Siddiqui MH, Alamri S, Nasir Khan M, Corpas FJ, Al-Amri AA, Alsubaie QD, Ali HM, Kalaji HM, Ahmad P. Melatonin and calcium function synergistically to promote the resilience through ROS metabolism under arsenic-induced stress. J Hazard Mater. 2020;398:122882.

57. Siddiqui MH, Al-Whaibi MH, Basalah MO. Role of nitric oxide in tolerance of plants to abiotic stress. Protoplasma. 2011;248:447-455.

58. Singh AP, Dixit G, Kumar A, Mishra S, Singh PK, Dwivedi S, Trivedi PK, Chakrabarty D, Mallick S, Pandey V, Dhankher OP, Tripathi RD. Nitric oxide alleviated arsenic toxicity by modulation of antioxidants and thiol metabolism in rice (Oryza sativa). Front Plant Sci. 2016;6:1272.

59. Singh HP, Batish DR, Kaur G, Arora K, Kohli RK. Nitric oxide (as sodium nitroprusside) supplementation ameliorates $\mathrm{Cd}$ toxicity in hydroponically grown wheat roots. Environ Exp Bot. 2008;63:158-167. 
60. Singla-Pareek SL, Yadav SK, Pareek A, Reddy MK, Sopory SK. Enhancing salt tolerance in a crop plant by overexpression of glyoxalase II. Transgenic Res. 2008;17:171-180.

61. Souri Z, Karimi N, Farooq MA, Sandalio LM. Nitric oxide improves tolerance to arsenic stress in Isatis cappadocica Shoots by enhancing antioxidant defenses. Chemosphere. 2020;239:124523.

62. Souri Z, Karimi N, Sandalio LM. Arsenic hyperaccumulation strategies: an overview. Front Cell Dev Biol. 2017;5:67.

63. Sumithra K, Jutur PP, Carmel BD, Reddy AR. Salinity-induced changes in two cultivars of Vigna radiata: responses of antioxidative and proline metabolism. Plant Growth Regul. 2006;50:11-22.

64. Velikova V, Yordanov I, Edreva A. Oxidative stress and some antioxidant systems in acid rain-treated bean plants - protective role of exogenous polyamines. Plant Sci. 2000;151:59-66.

65. Wang Q, Liang X, Dong Y, Xu L, Zhang X, Hou J, Fan Z. Effects of exogenous nitric oxide on cadmium toxicity, element contents and antioxidative system in perennial ryegrass. Plant Growth Regul. 2013;69:11-20.

66. Wang TT, Shi ZQ, Hu LB, Xu XF, Han FX, Zhou LG, Chen J. Thymol ameliorates cadmium-induced phytotoxicity in the root of rice (Oryza sativa) seedling by decreasing endogenous nitric oxide generation. J Agric Food Chem. 2017;65:7396-7405.

67. Xiong J, Fu G, Tao L, Zhu C. Roles of nitric oxide in alleviating heavy metal toxicity in plants. Arch Biochem Biophys. 2010;497:13-20.

68. Yadav SK. Heavy metals toxicity in plants: An overview on the role of glutathione and phytochelatins in heavy metal stress tolerance of plants. S Afr J Bot. 2010;76:167-179.

69. Yadav SK, Singla-Pareek SL, Reddy M, Sopory S. Methylglyoxal detoxification by glyoxalase system: a survival strategy during environmental stresses. Physiol Mol Biol Plants. 2005;11(1):1-11.

70. Yang H, Mu J, Chen L, Feng J, Hu J, Li L, Zhou J.-M, Zuo J. S-Nitrosylation Positively Regulates Ascorbate Peroxidase Activity during Plant Stress Responses. Plant Physiol. 2015;167:1604-1615.

71. Zhao FJ, McGrath SP, Meharg AA. Arsenic as a food chain contaminant: mechanisms of plant uptake and metabolism and mitigation strategies. Annu Rev Plant Biol 2010;61:535-559.

72. Talukdar, D. Plant growth and leaf antioxidant metabolism of four elite grass pea (Lathyrus sativus) genotypes, differing in arsenic tolerance. Agric Res. 2013;2:330-339.

\section{Figures}



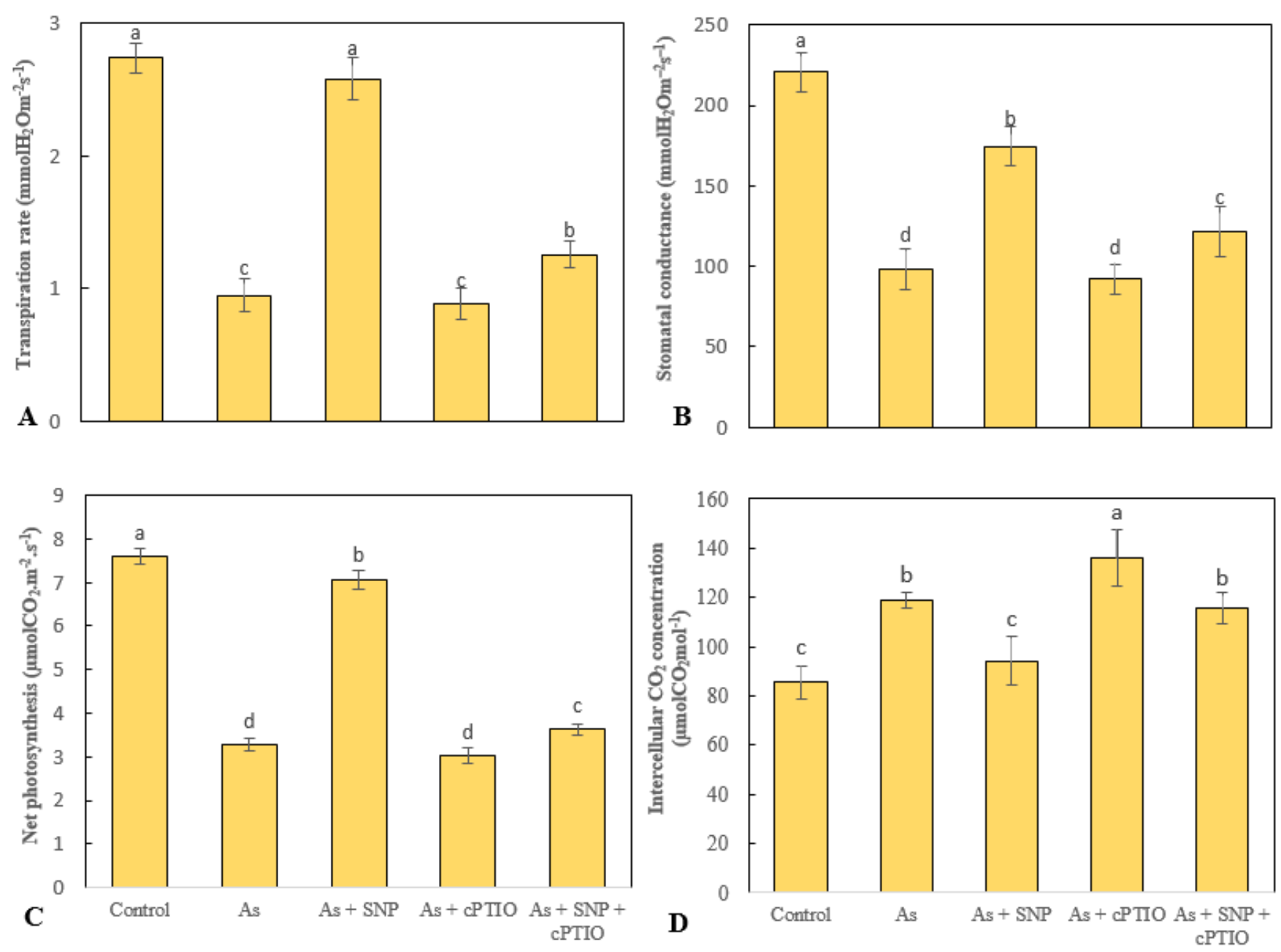

Figure 1

Effect of arsenic (As, $10 \mathrm{mg} / \mathrm{L}$ ) alone or in combination with nitroprusside (SNP,100 $\mu \mathrm{M})$ and 2-(4carboxyphenyl)-4,4,5,5-tetramethylimidazoline-1-oxyl-3-oxide (cPTIO, $200 \mu \mathrm{M})$ on transpiration rate (A), stomatal conductance (B), net photosynthesis (C) and intercellular CO2 concentration (D) in tomato seedlings. Values (means $\pm S D, n=5)$ followed by the same letter are not significantly different $(P<0.05$; LSD test) 

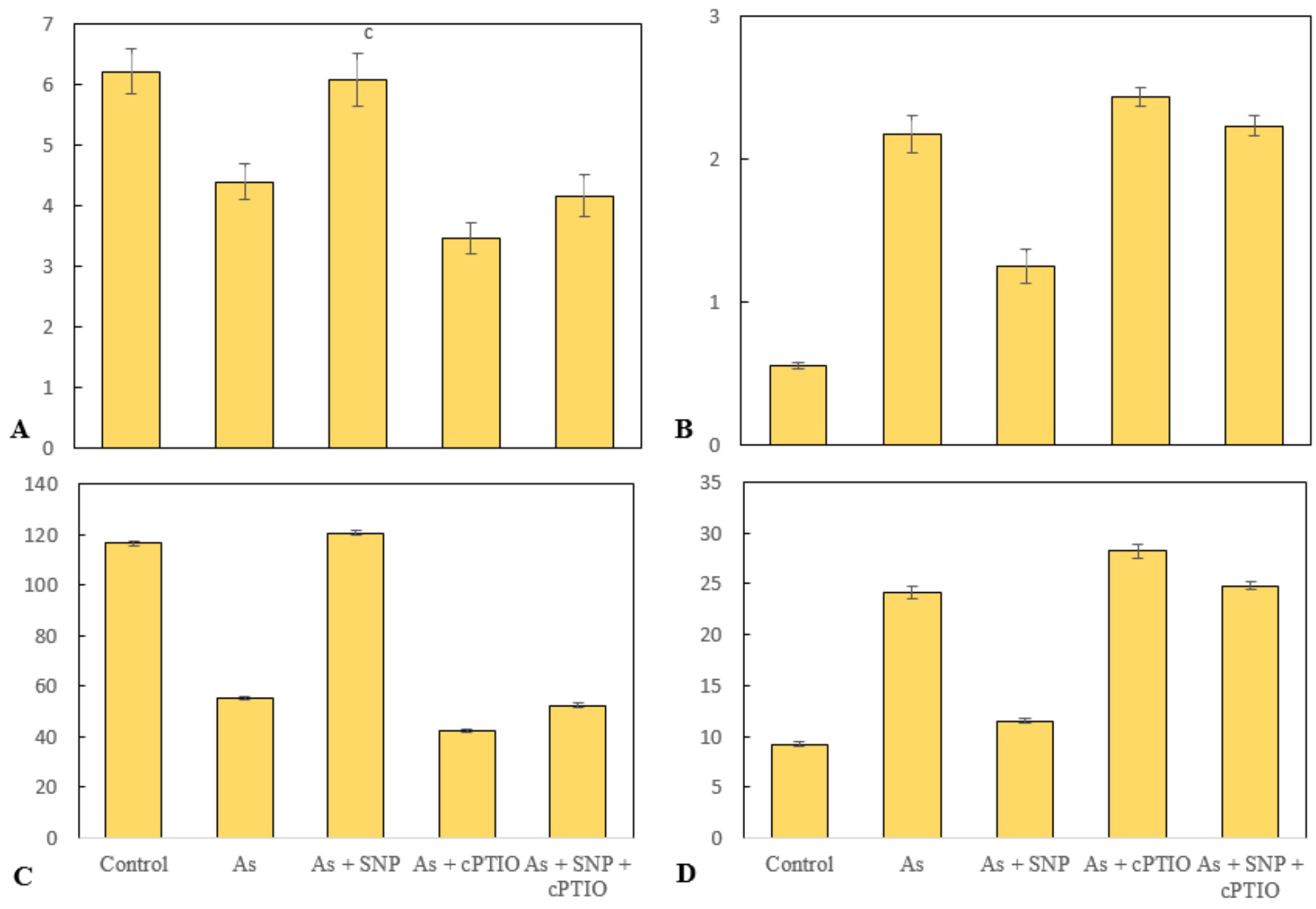

Figure 2

Effect of arsenic (As, $10 \mathrm{mg} / \mathrm{L})$ alone or in combination with nitroprusside (SNP,100 $\mu \mathrm{M})$ and 2-(4carboxyphenyl)-4,4,5,5-tetramethylimidazoline-1-oxyl-3-oxide (CPTIO, $200 \mu \mathrm{M})$ on the activity of proline dehydrogenase (PDH, A), 1-pyrroline-5-carboxylate synthetase (P5CS, B), $\delta$-aminolevulinic acid dehydratase $(\delta-A L A D, C)$ and chlorophyllase (Chlase, $D)$ in tomato seedlings. Values (means $\pm S D, n=5$ ) followed by the same letter are not significantly different $(P<0.05$; LSD test) 

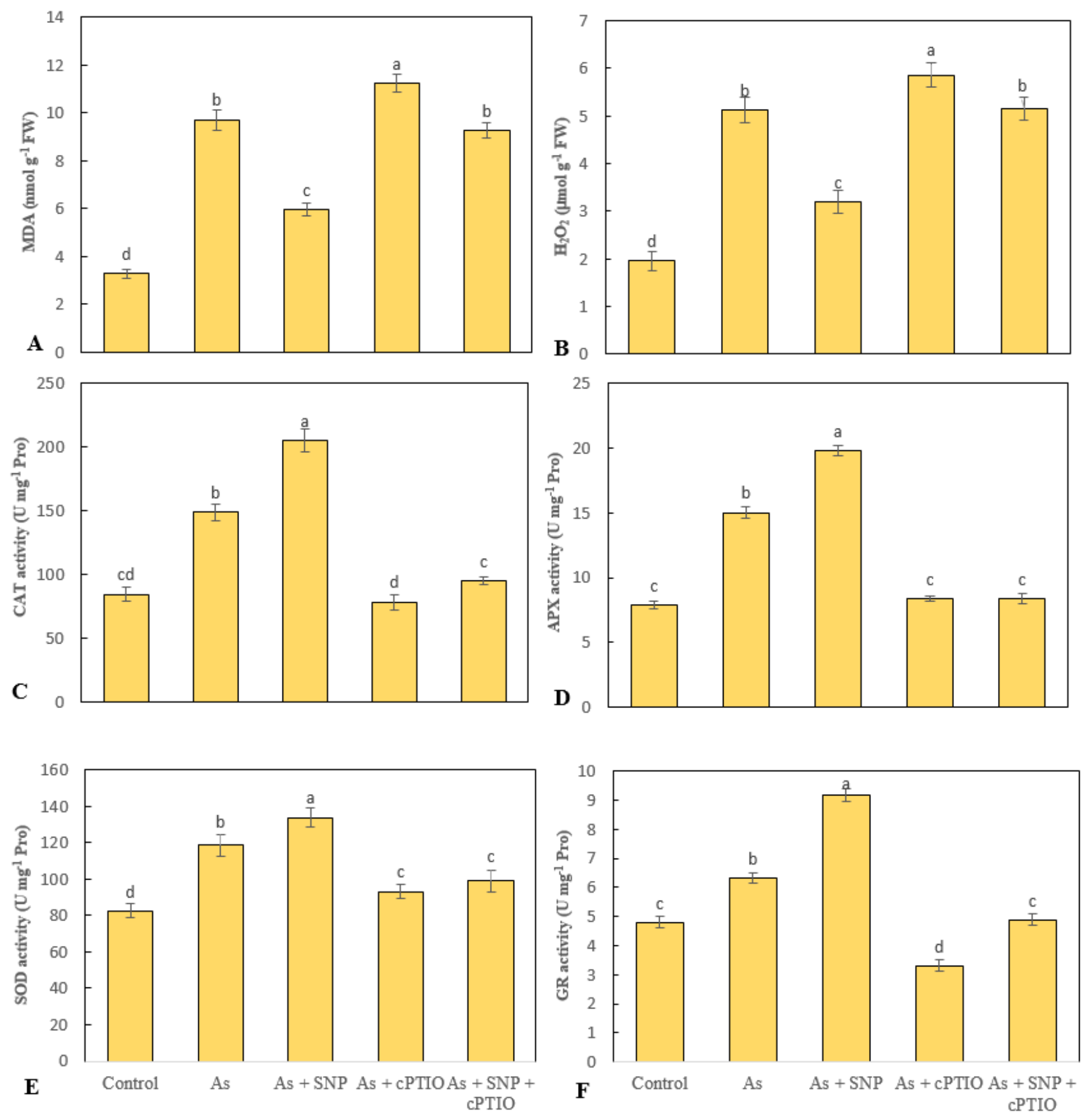

\section{Figure 3}

Effect of arsenic (As, $10 \mathrm{mg} / \mathrm{L})$ alone or in combination with nitroprusside (SNP,100 $\mu \mathrm{M})$ and 2-(4carboxyphenyl)-4,4,5,5-tetramethylimidazoline-1-oxyl-3-oxide (cPTIO, $200 \mu \mathrm{M}$ ) on the content of malondialdehyde (MDA, A) and hydrogen peroxide (H2O2, B), and the activity of catalase (CAT, C), and ascorbate peroxidase (APX, D) superoxide dismutase (SOD, E) and glutathione reductase (GR, F) in the leaves of tomato seedlings. Values (means $\pm S D, n=5$ ) followed by the same letter are not significantly different $(P<0.05 ;$ LSD test $)$ 

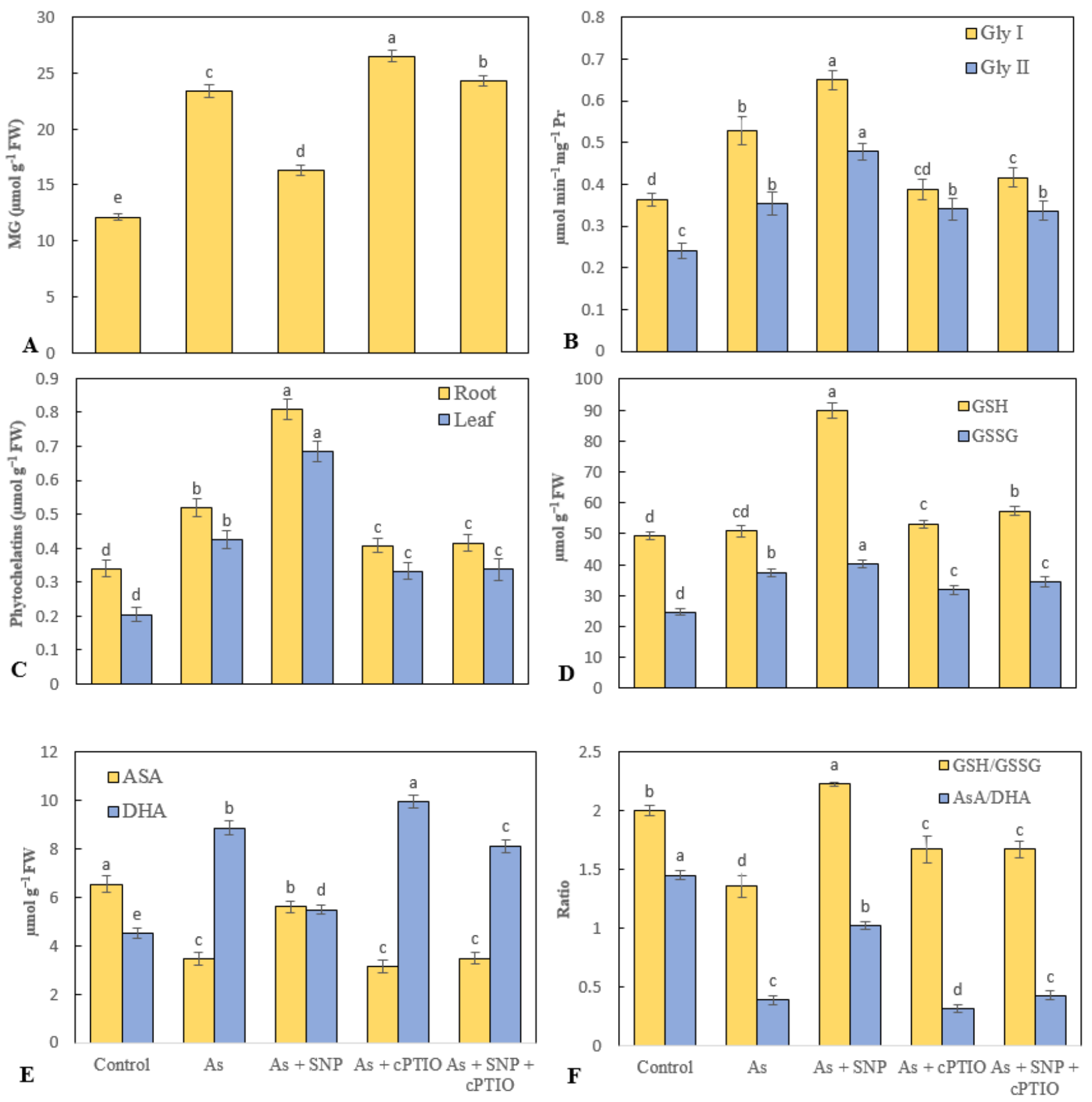

\section{Figure 4}

Effect of arsenic (As, $10 \mathrm{mg} / \mathrm{L}$ ) alone or in combination with nitroprusside (SNP,100 $\mu \mathrm{M})$ and 2-(4carboxyphenyl)-4,4,5,5-tetramethylimidazoline-1-oxyl-3-oxide (cPTIO, $200 \mu \mathrm{M}$ ) on the content of methylglyoxal (MG, A), the activity of glyoxalase I and II (Gly I and II, B), phytochelatins (C), reduced and oxidized glutathione (GSH and GSSG, D), reduced and oxidized ascorbic acid (AsA and DHA, E), and ratios of ASA/DHA and GSH/GSSG (F) in the leaves of tomato seedlings. Values (means $\pm S D, n=5$ ) followed by the same letter are not significantly different $(P<0.05$; LSD test) 

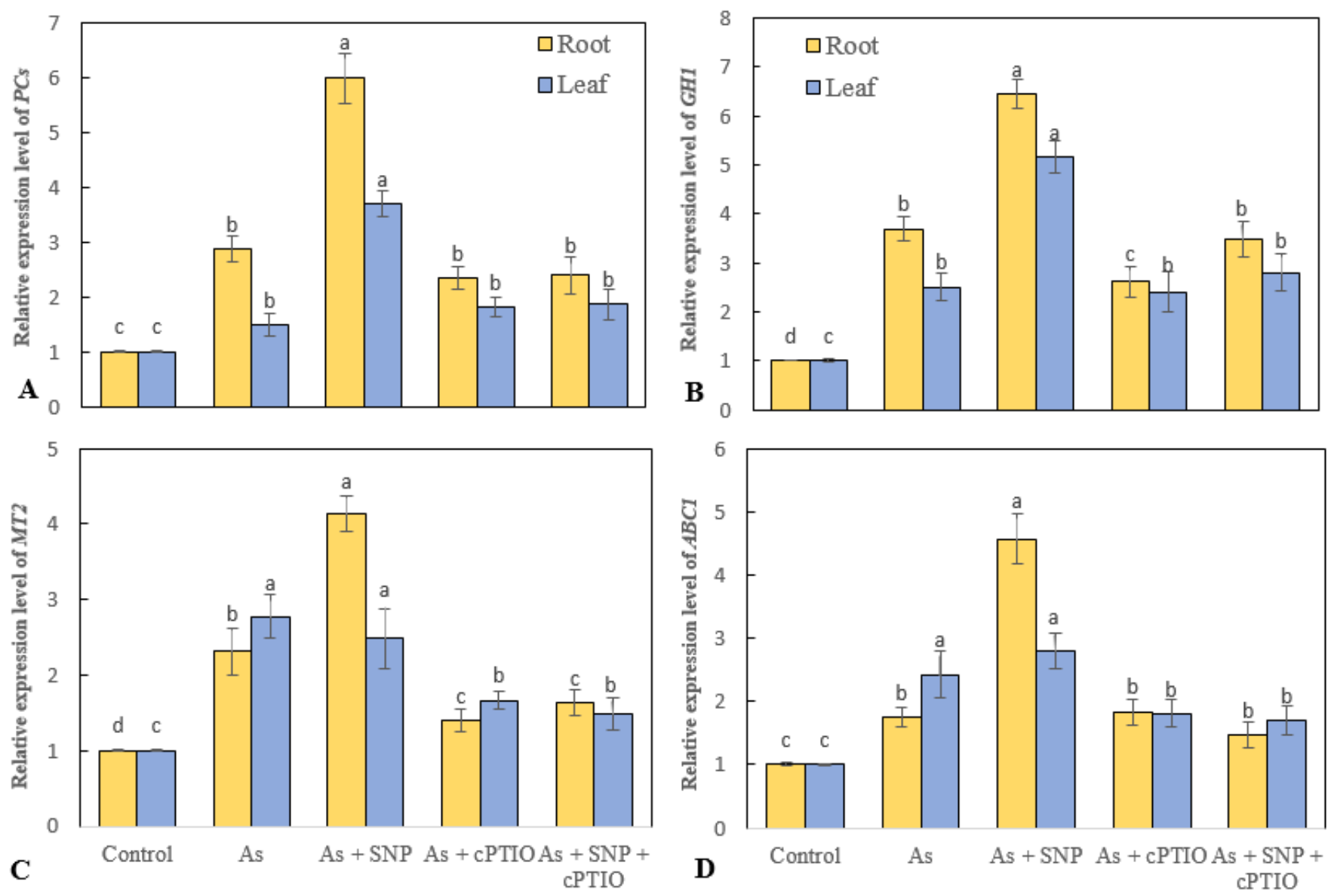

Figure 5

Effect of arsenic (As, $10 \mathrm{mg} / \mathrm{L})$ alone or in combination with nitroprusside (SNP,100 $\mu \mathrm{M})$ and 2-(4carboxyphenyl)-4,4,5,5-tetramethylimidazoline-1-oxyl-3-oxide (cPTIO, $200 \mu \mathrm{M})$ on the expression of phytochelatin synthase (PCS, A), gamma-glutamylcysteine synthetase (GSH1, B), type 2 metallothionein $(M T 2, C)$ and $A B C$ transporter $C$ family member $2(A B C 1, D)$ in the roots and leaves of tomato seedlings. Values (means $\pm S D, n=3$ ) followed by the same letter are not significantly different $(P<0.05$; LSD test)

\section{Supplementary Files}

This is a list of supplementary files associated with this preprint. Click to download.

- Graphicalabstract.docx 